\title{
江西武夷山国家级自然保护区林下鸟类和兽类资 源的红外相机监测
}

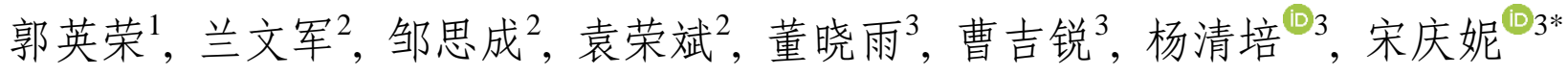

1. 江西省自然保护地建设中心，南昌 330038；2. 江西武夷山国家级自然保护区管理局，江西上饶 334515; 3. 江西农业大学林学院，南昌 330045

摘要: 红外相机技术已成为野生动物监测的一种有效手段, 在自然保护区物种资源的清查中具有重要的应用价值。为了进一 步完善江西武夷山国家级自然保护区鸟兽的编目信息, 2016年11月至2018年8月, 我们按样线法布设了52台红外相机进行连 续监测。本次调查累计 18,417 个相机工作日，拍摄到独立有效照片 8,908 张，记录到野生兽类与鸟类共62种，其中兽类20种，隶 属5目13科，鸟类42种，隶属5目14科。国家I级重点保护野生动物有2种, 即黑鹿(Muntiacus crinifrons)和黄腹角雉(Tragopan caboti), 国家II级重点保护野生动物有亚洲黑熊(Ursus thibetanus)、毛冠鹿(Elaphodus cephalophus)和中华鬛羚(Capricornis milneedwardsii)等10种。被IUCN 红色名录评估为易危的有 4 种, 近危的 5 种。兽类相对多度指数居于前三位的依次为小鹿 (Muntiacus reevesi)、藏酋猴 (Macaca thibetana) 和野猪 (Sus scrofa); 鸟类相对多度指数位于前三位的是白酠(Lophura nycthemera)、紫啸鸫(Myophonus caeruleus)和黑领噪鹋(Garrulax pectoralis)。物种相对多度指数沿海拔梯度呈现中部高、两 侧低的单峰模式, 以800-1,200 m的区域最高。本文结果可为保护区的野生动物资源清查提供基础数据，也为后续保护区管理 政策的制定提供参考。

关键词：野生动物监测; 珍稀动物; 相对多度指数; 中域效应假说; 物种多样性

郭英荣, 兰文军, 邹思成, 袁荣斌, 董晓雨, 曹吉锐, 杨清培, 宋庆妮 (2021) 江西武夷山国家级自然保护区林下鸟类和兽类资源的红外相机监测. 生 物多样性, 29, 811-818. doi: 10.17520/biods.2020307.

Guo YR, Lan WJ, Zou SC, Yuan RB, Dong XY, Cao JR, Yang QP, Song QN (2021) Camera-trapping survey of wild mammals and ground-dwelling birds in the Jiangxi Wuyishan National Nature Reserve, China. Biodiversity Science, 29, 811-818. doi: 10.17520/biods.2020307.

\section{Camera-trapping survey of wild mammals and ground-dwelling birds in the Jiangxi Wuyishan National Nature Reserve, China}

Yingrong Guo ${ }^{1}$, Wenjun Lan $^{2}$, Sicheng Zou², Rongbin Yuan², Xiaoyu Dong ${ }^{3}$, Jirui Cao ${ }^{3}$, Qingpei Yang ${ }^{\mathbb{D} 3}$, Qingni Song ${ }^{(1)} 3^{*}$

1 Construction Center of Jiangxi Natural Reserves, Nanchang 330038

2 Administration of Jiangxi Wuyishan National Nature Reserve, Shangrao, Jiangxi 334515

3 College of Forestry, Jiangxi Agricultural University, Nanchang 330045

\section{ABSTRACT}

Aim: We aim to investigate the biological inventory of large and medium-sized mammals and ground-dwelling birds in the Jiangxi Wuyishan National Nature Reserve using camera-trapping techniques.

Method: 52 camera-traps were placed between $531 \mathrm{~m}$ and 2,051 m a.s.l. from November 2016 to June 2018. The relative abundance index was used to evaluate the population sizes of different species.

Results: A total of 8,908 independent photographs were taken with a sampling effort of 18,417 camera-days. We identified 20 wild mammal species ( 5 orders and 13 families) and 42 bird species ( 5 orders and 14 families). Of all the detected species, 2 species are listed as first-class National Protected Wildlife (Muntiacus crinifrons and Tragopan caboti), and 10 species are listed as second-class National Protected Wildlife (Ursus thibetanus, Elaphodus

收稿日期: 2020-07-31; 接受日期: 2020-11-22

基金项目：江西省科技计划项目(20151BBG70025)和国家自然科学基金(41807018)

* 通讯作者 Author for correspondence. E-mail: songqingni@126.com 
cephalophus, Capricornis milneedwardsii, and others). Four species were listed as Vulnerable and five as Near Threatened according to the IUCN Red List. Based on the relative abundance index, the three most abundant mammal species were Muntiacus reevesi, Macaca thibetana and Sus scrofa; and the three most detected bird species were Lophura nycthemera, Myophonus caeruleus and Garrulax pectoralis. The relative abundance index of species presents a unimodal pattern along the altitude gradient with the largest value being in the area of 800-1,200 $\mathrm{m}$.

Conclusion: These findings indicate Jiangxi Wuyishan Nature Reserve has high species diversity and rich rare and endangered species, especially in the mid-altitude areas. This study provides an important foundation for further biodiversity investigation and wildlife management measures of reserves.

Key words: wildlife monitoring; rare animals; relative abundance index; mid-domain effect hypothesis; species diversity

自然保护区是我国生物多样性保护的核心区 域。对保护区的野生动物进行调查和编目, 摸清其 生物多样性资源家底、监测动物种群动态, 有利于 野生动物保护管理与政策的制定(马克平, 2015; 肖 治术, 2016)。目前我国自然保护区对野生动物资源 的调查主要采用样线法或样带法, 收集到的物种数 量、空间分布和生活节律等信息存在一定的偶然 性、不确定性和滞后性, 无法系统反映某一地区的 野生动物资源现状。与传统野生动物调查方法相 比, 红外相机技术是一种非损伤性的物种调查与记 录技术, 具有准确性、持续性和隐蔽性等优点, 已 成为自然保护区生物多样性监测的最有效工具之 一(李晟等, 2014; 王丞等, 2019)。近年 来, 红外相机 技术在监测动物多样性(陈声文等, 2016)、动物种群 密度(程松林等, 2017)、活动节律(Frey et al, 2017) 和物种空间分布规律(李广良等, 2014)等方面发挥 了重要作用。

江西武夷山国家级自然保护区(以下简称江西 武夷山保护区)地处武夷山脉北段的西北坡, 属于 森林生态系统类型自然保护区。在亚热带季风气 候、海拔、复杂地形的共同作用下, 区内动植物资 源丰富, 珍稀濒危物种繁多, 如中国特有种黑鹿 (Muntiacus crinifrons)和黄腹角雉(Tragopan caboti) 等。然而, 有关兽类与鸟类多样性的研究仅于保护 区综合科考时进行了调查与报道(刘信中, 2003), 且 采用的是传统调查方法, 而借助红外相机监测动物 的研究相对较少。程松林等(2013b)首次利用红外相 机提供了黑鹿存在与分布的准确信息, 随后他们又 利用红外相机调查了黄腹角雉的生物学习性及海 拔分布特征(程松林等, 2017)。但是这些研究主要是 针对单个物种, 无法反映保护区内大型兽类与鸟类 资源的现状。多种珍稀动物如华南虎(Panthera tigris
amoyensis)、云豹(Neofelis nebulosa)、豹(Panthera pardus)等, 多年未见确丵证据, 因此亟需对当前保 护区内动物资源和分布的真实情况进行深入了解。

为此, 本研究采用红外相机技术对区内大中型 兽类及林下鸟类资源进行连续监测, 旨在: (1)掌握 江西武夷山保护区大中型兽类和林下鸟类资源现 状; (2)分析兽类和林下鸟类的群落组成、相对数量 和空间分布特征, 以期为今后的科学研究及保护计 划的制定提供参考。

\section{研究方法}

\section{1 研究区概况}

江西武夷山保护区位于江西省东北部铅山县 (2748'11"-2800'35" N, 11739'30"-117º55'47" E), 地处武夷山脉北段、主峰黄岗山(海拔2,160 m)的西 北坡, 与福建武夷山国家级自然保护区接壤。该保 护区成立于 2002 年, 面积为 16,007 ha, 其中核心区 面积 4,835 ha, 缓冲区面积 2,021 ha, 实验区面积 9,151 ha (程松林等, 2009)。研究区属亚热带中部季 风气候带, 年均气温 $14.2^{\circ} \mathrm{C}$, 年均降水量 $2,583 \mathrm{~mm}$, 每年降水日约 $200 \mathrm{~d}$, 相对湿度 $84.0 \%$, 蒸发量 $778 \mathrm{~mm}$, 无霜期 $240 \mathrm{~d}$ 左右。区内动植物资源丰富, 群落类型多样, 原生状态保存完整, 海拔 $1,000 \mathrm{~mW}$ 上没有居民点和生产活动(程松林等, 2017)。植被 垂 直带谱发育典型, 从低海拔至高海拔依次为毛竹 (Phyllostachys edulis)林、常绿阔叶林、常绿落叶阔 叶混交林、针阔叶混交林、针叶林、山顶苔藓矮林、 山顶灌从草甸。毛竹林的优势种为毛竹; 常绿阔叶 林的优势树种主要为丝栗栲(Castanopsis fargesii)、 甜槠(Castanopsis eyrei)和多脉青冈(Cyclobalanopsis multinervis)等; 常绿落叶阔叶混交林的优势树种为 木荷(Schima superba)、多脉青冈、枫香(Liquidambar 
formosana)和光皮桦(Betula luminifera) 等; 针阔混 交林的优势针叶树为黄山松(Pinus taiwanensis)和南 方铁杉(Tsuga chinensis), 阔叶树主要是多脉青冈、 木荷和包果柯(Lithocarpus cleistocarpus)等; 针叶林 的优势树种为黄山松、南方铁杉和杉木 (Cunninghamia lanceolate); 灌丛的优势种主要为肿 节少穗竹(Oligostachyum oedogonatum)、鹿角杜鹃 (Rhododendron latoucheae) 和云锦杜鹃 ( $R$. fortunei)(刘信中, 2003)。保护区记录兽类8目27科77 种，鸟类18目 47 科 223 种，包括黑鹿、亚洲黑熊 (Ursus thibetanus)、黄腹角雉和白颈长尾雉 (Syrmaticus ellioti)等国家重点保护野生动物(刘信 中, 2003)。

\section{2 数据采集}

2016年11月至2018年8月, 根据巡护经验及生 境状况, 我们在保护区内选择11条样线, 在每条样 线上分别设置3-7个红外相机位点, 同一样线内两 台相机的间隔距离至少 $200 \mathrm{~m}$ (图1)。调查共布设54 台相机, 主要是在动物活动较频繁的地方, 如兽 道、水源地附近以及采食地, 海拔范围为5312,051 m。有2台相机自第一次安装后被盗, 剩下52台 相机进行持续监测, 相机位点的基本信息见附录1。

相机安装过程如下：选择合适树干, 将相机捆 在距离地面 $50-80 \mathrm{~cm}$ 的高度上。相机与兽道呈锐角 或正对水源, 避开阳光直射。适当清理相机前方可
能干扰拍摄或导致误触发的树枝、灌草, 留出动物 活动空间。相机型号为猎科Lt16210, 设置模式为: 拍照 + 视频(连拍 2 张 $+20 \mathrm{~s}$ 视频), 时间间隔 $1 \mathrm{~s}$; 灵敏度中。对每台相机进行编号, 记录它们的放置 日期、经纬度、海拔、功能区位置、森林类型以及 乔木、灌木和草本的种类及密度等信息。相机安装 后每3个月检查1次，收集数据并更换电池。

\section{3 数据处理}

将照片和视频数据根据拍摄的对象划分为兽 类、鸟类、家畜及人4类，统计清晰可识别的野生兽 类和鸟类物种。兽类分类参考《中国哺乳动物多样 性及地理分布》(蒋志刚等, 2015)。鸟类的鉴定参考 《中国鸟类分类与分布名录 (第三版)》(郑光美, 2017)。物种保护等级参考《国家重点保护野生动物 名录》(国家林业和草原局农业农村部公告(2021年 第3号), http://www.forestry.gov.cn/)、IUCN红色名录 (https://www.iucnredlist.org) 及 CITES 附录 (http:// www.cites.gov.cn/)。

我们定义1台红外相机在野外正常工作 $24 \mathrm{~h}$ 为 1 个相机工作日(camera day, CD)。采用稀疏化曲线 (rarefaction curve)拟合兽类、鸟类与相机工作日之 间的关系以检验取样是否充分。物种的相机位点出 现率(camera occurrence rate)反映不同物种在监测区 域内的分布或活动范围大小，它指的是某物种被拍 到的相机总数占正常工作相机总数的百分率。将同

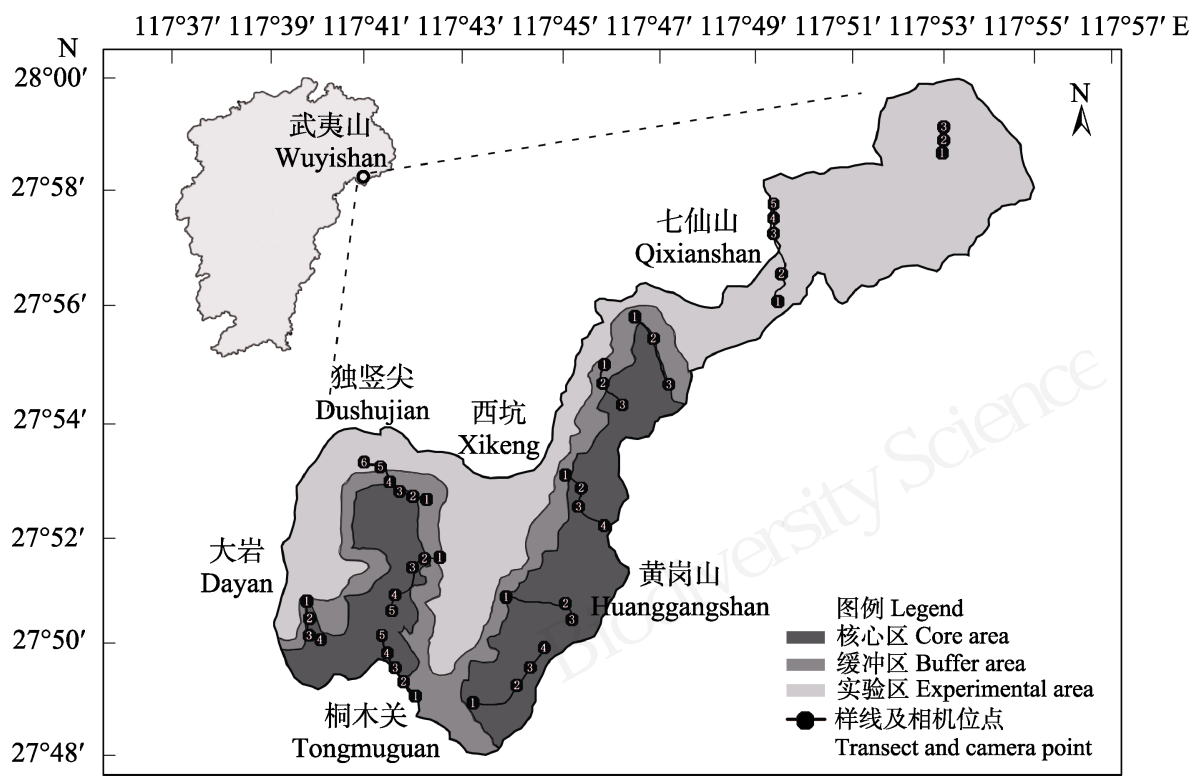

图1 江西武夷山国家级自然保护区红外相机安装位点分布图

Fig. 1 Sites of infra-red camera-trapping in the Jiangxi Wuyishan National Nature Reserve 
一相机位点 $15 \mathrm{~min}$ 内连续拍摄到的同一个体的有效 照片 (或视频) 记为 1 张独立照片 (independent photograph, IP)。相对多度指数(relative abundance index, RAI)的计算公式如下(李晟等, 2014):

$$
\mathrm{RAI}=\frac{A}{N} \times 1,000
$$

其中, $A$ 表示某物种所有相机位点的独立有效照片 数, $N$ 为所有相机位点的有效工作日。通过计算不同 海拔与功能区动物的相对多度指数, 比较不同生境 条件下动物的多样性。

利用 Shannon-Wiener多样性指数 $\left(H^{\prime}\right)$ 分析不同 海拔和功能区的动物多样性, 计算公式如下(汪国 海等, 2016):

$$
H^{\prime}=-\sum_{i=1}^{s} P_{i} \ln P_{i}
$$

式中, $S$ 是物种数目, $P_{i}$ 为第 $\mathrm{i}$ 个物种的独立有效照片 数占独立有效照片总数的比例。

\section{2 结果}

52 台红外相机累计监测 18,417 个相机工作日, 共拍摄到92,784张照片(视频也被归为照片处理), 包括野生动物有效照片 22,132张, 独立照片8,908张, 兽类照片 7,624 张, 占比 $85.6 \%$, 鸟类照片 1,284 张 (14.4\%)。单台相机所记录的物种数最少为 1 种, 最 多为 30 种, 所有相机平均记录的物种数为 $11 \pm 5$ 种。 调查共记录到62种野生动物, 隶属10目27科, 其中 兽类20种，鸟类42种(附录2，附录3)。

通过物种数与相机工作日之间的拟合稀疏曲 线可以看出, 兽类物种数随相机工作日的增加变化 比较平稳, 大约在 2,000 个相机工作日趋于饱和; 而 鸟类物种数在 1,000-6,000个相机工作日期间增加 较快, 但在6,000个工作日后增加缓慢(图2), 大约在 12,000 个相机工作日后仍有少量增加, 表明本研究 兽类监测时间已充足，鸟类还需要延长监测时间。

\section{1 物种组成}

共鉴定出20种兽类，隶属于5目13科(附录2), 其中食肉目物种数最多, 有 8 种, 占兽类物种总数 的 $40.0 \%$; 其次是偶蹄目 (5种), 占兽类物种总数的 $25.0 \%$; 啮齿目 5 种，灵长目和兔形目各1种。夜间拍 到的鼠科动物由于个体较小, 不易辨别, 统一归为 鼠类。兽类中列为国家I级重点保护野生动物的有 1

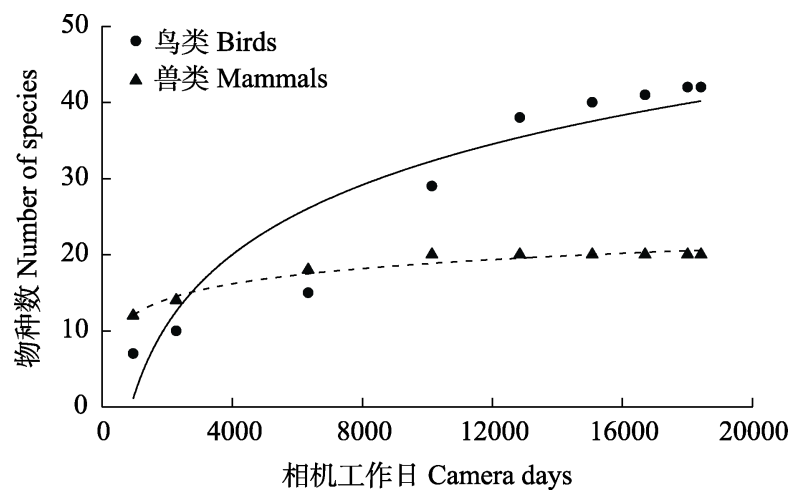

图2 江西武夷山国家级自然保护区内兽类与林下鸟类物种 数量与相机工作日拟合的稀疏化曲线

Fig. 2 Rarefaction curves for estimating species number of mammals and ground-dwelling birds with increased camera days in the Jiangxi Wuyishan National Nature Reserve

种(黑鹿), 国家II级的6种, 即亚洲黑熊、藏酋猴 (Macaca thibetana)、毛冠鹿(Elaphodus cephalophus)、中华鬛羚(Capricornis milneedwardsii)、赤狐 (Vulpes vulpes)和黄喉貂(Martes flavigula)。被列入 CITES附录I的有3种(黑鹿、亚洲黑熊和中华镾羚)、 附录II的有1种(藏酋猴)。在IUCN物种红色名录中, 被评估为易危(VU)级别的3种, 即黑鹿、亚洲黑熊和 猪獾(Arctonyx collaris), 被评估为近危(NT)的4种, 即藏酋猴、中华鬌羚、黄腹鼠由(Mustela kathiah)和毛 冠鹿，其余12种被评估为无危(LC)。中国特有种4 种, 即小鹿(Muntiacus reevesi)、黑鹿、藏酋猴和华 南兔(Lepus sinensis)。

鉴定出的 42 种林下鸟类分属 5 目 14 科，其中雀 形目种类最多(31种), 占鸟类物种总数的 $73.8 \%$; 鸡 形目5种，殠形目 3 种，隼形目 2 种，鸽形目 1 种。鸟类 中列为国家I级重点保护野生动物的1种(黄腹角雉), 国家II级的4种, 即白闲(Lophura nycthemera)、勺鸡 (Pucrasia macrolopha)、凤头鹰 (Accipiter trivirgatus) 和鹰雕(Spizaetus nipalensis)。被CITES附录I收录的 有 1 种, 为黄腹角雉, 附录II有 4 种, 即凤头鹰、鹰雕、 画眉 (Garrulax canorus) 和红嘴相思鸟 (Leiothrix lutea)。在IUCN物种红色名录中, 黄腹角雉被评估 为易危，白眉山椨鸪(Arborophila gingica)被评估为 近危，其余 40 种都被评估为无危。另外，中国特有 鸟类有黄腹角雉、白眉山椨鸪、灰胸竹鸡 (Bambusicola thoracicus) 和棕噪鹋 (Garrulax poecilorhynchus)。 
表1 江西武夷山国家级自然保护区兽类和林下鸟类在不同海拔与功能区的分布规律

Table 1 Species diversity of mammals and ground-dwelling birds by camera-trapping in different elevation gradients and different functional zones in the Jiangxi Wuyishan National Nature Reserve

\begin{tabular}{|c|c|c|c|c|c|c|}
\hline $\begin{array}{l}\text { 环境变量 Environmental } \\
\text { variables }\end{array}$ & $\begin{array}{l}\text { 相机位点数 No. } \\
\text { of camera sites }\end{array}$ & $\begin{array}{l}\text { 相机工作日 } \\
\text { Camera days }\end{array}$ & $\begin{array}{l}\text { 独立照片数 No. } \\
\text { of independent } \\
\text { photographs }\end{array}$ & $\begin{array}{l}\text { 物种数 No. } \\
\text { of species }\end{array}$ & $\begin{array}{l}\text { 相对多度指数 Relative } \\
\text { abundance index (RAI) }\end{array}$ & $\begin{array}{l}\text { Shannon-Wiener指 } \\
\text { 数 Shannon-Wiener } \\
\text { index }\left(H^{\prime}\right)\end{array}$ \\
\hline \multicolumn{7}{|l|}{ 海拔 Elevation } \\
\hline$<800 \mathrm{~m}$ & 4 & 1,257 & 573 & 21 & 455.8 & 1.949 \\
\hline $800-1,000 \mathrm{~m}$ & 8 & 3,425 & 1,980 & 41 & 578.1 & 2.155 \\
\hline $1,000-1,200 \mathrm{~m}$ & 12 & 4,427 & 2,476 & 46 & 559.0 & 1.785 \\
\hline $1,200-1,400 \mathrm{~m}$ & 9 & 2,967 & 1,295 & 27 & 436.4 & 1.602 \\
\hline $1,400-1,600 \mathrm{~m}$ & 7 & 2,776 & 1,174 & 36 & 422.9 & 2.031 \\
\hline $1,600-1,800 \mathrm{~m}$ & 7 & 2,288 & 735 & 30 & 321.2 & 1.808 \\
\hline$>1,800 \mathrm{~m}$ & 5 & 1,277 & 675 & 19 & 528.6 & 1.520 \\
\hline \multicolumn{7}{|l|}{ 功能区划 Functional zone } \\
\hline 核心区 Core zone & 30 & 9,915 & 4,528 & 47 & 456.8 & 1.910 \\
\hline 缓冲区 Buffer zone & 11 & 4,153 & 2,205 & 38 & 531.4 & 1.863 \\
\hline 实验区 Experimental zone & 11 & 4,349 & 2,164 & 44 & 499.4 & 2.324 \\
\hline
\end{tabular}

\section{2 物种相对多度}

在红外相机记录的20种野生兽类中, 相对多度 指数排前五位的依次是小鹿 $(\mathrm{RAI}=224.20)$ 、藏尊 猴 $(\mathrm{RAI}=41.32)$ 、野猪 $($ Sus scrofa, RAI = 21.28)、华南 兔 $($ Lepus sinensis, RAI = 19.66)、黄腹鼠 $(\mathrm{RAI}=$ 9.06)。相机位点出现率位于前五位的依次是小鹿(49 个位点)、藏酋猴(43个位点)、野猪(37个位点)、中 华䯷羚(22个位点)和毛冠鹿(18个位点)。统计兽类的 集群活动发现, 藏酋猴、野猪均有明显的集群现象, 藏酋猴最多有 23 只同时活动, 3只以上活动的照片 有 165 张, 占其照片总数的 $21.7 \%$; 野猪最多有 9 只 同时活动, 3 只以上的照片有 47 张, 占其照片总数的 $12.0 \%$ 。

林下鸟类中相对多度指数排前五位的依次是 白闲(RAI = 23.40)、紫啸冻 (Myophonus caeruleus, $\mathrm{RAI}=17.16)$ 、黑领噪鹛 (Garrulax pectoralis, RAI = 6.24)、黄腹角雉 $(\mathrm{RAI}=5.27)$ 和棕噪鹛 $(\mathrm{RAI}=3.58)$ 。 这 5 种鸟类的相机位点出现率也最高, 其中白注在 45台相机中拍摄到, 占所有机位的 $86.8 \%$, 紫啸鸫 和黄腹角雉被 18 台相机拍摄，占总机位的 $34.6 \%$, 黑领噪鹛在25台相机中出现, 棕噪鹛被12台相机拍 摄。白㭤、黑领噪鹤和棕噪鸤存在集群活动情况, 最 大数量分别为 10 只、 6 只和 7 只, 3 只以上独立照片分 别为 40 张、 22 张和 26 张。

调查结果显示, 物种数、相对多度指数和
Shannon-Wiener指数沿海拔梯度大体呈现中部高、 两侧低的单峰模式, 800-1,200 m的中等海拔是兽类 和林下鸟类多样性最高的区域(表1)。不同功能区域 的物种数量、相对多度指数和多样性指数也具有一 定的差异, 核心区、缓冲区和实验区记录的物种数 分别是47、38和44种。相对多度指数为缓冲区最高, 实验区居中, 核心区最低; Shannon-Wiener指数为 实验区最高, 缓冲区与核心区相对较低(表1)。

\section{3 讨论}

本研究共鉴定出 20 种兽类, 隶属于 5 目 13 科, 与红外相机调查的福建武夷山自然保护区兽类名 录(5目10科19种)接近 ${ }^{(1)}$, 但与江西武夷山保护区科 考记录(刘信中, 2003)相比, 还有1种偶蹄目和13种 食肉目兽类未调查到, 它们是獐 (Hydropotes inermis) 、狼 (Canis lupus)、貉 (Nyctereutes procyonoides)、豹(Cuon alpinus)、华南虎、豹、云 豹、豹猫(Prionailurus bengalensis)、金猫 (Catopuma temminckii)、大灵猫(Viverra zibetha)、小灵猫 (Viverricula indica)、亚洲狗獾(Meles leucurus)、鼠 獾(Melogale moschata)和水獭(Lutra lutra)。豹猫、 狗獾和鼠獾在保护区日常监测中有记录(程松林等, 2013a), 而另外10种在过去10年间没有确丵的分布

(1) 王海婴 (2017) 福建武夷山赤鹿(Muntiacus vaginalis)活动节律和行 为时间分配的研究. 硕士学位论文, 厦门大学, 厦门. 
证据, 其主要原因可能是: (1)保护区在建立前由林 场管理经营, 对树木过度砍伐导致兽类的栖息地面 积减小, 并呈现破碎化, 加重了兽类的暴露程度并 减少了食物来源; (2)由于人为活动的干扰和长期的 偷猎压力, 导致这些物种的种群密度在保护区及周 边地区已经非常低, 甚至出现局域灭绝。

3 种鹿科动物(小鹿、毛冠鹿和黑鹿)在江西武夷 山保护区的相对多度与分布范围差异较大(附录2)。 小鹿的RAI占绝对优势, 相机位点出现率达 $94.2 \%$, 说明小鹿在保护区的生存状态优良、种群密度大、 分布广。毛冠鹿的RAI只有小鹿的 $1.7 \%$, 在 $34.6 \%$ 的 相机位点有记录, 黑鹿的RAI尚不到小鹿的 $1 \%$, 仅 在19.2\%的位点有记录, 说明毛冠鹿和黑鹿的种群 密度处于较低水平。程松林(2013b)的调查和本次监 测均发现黑鹿在七仙山海拔 $1,000 \mathrm{~m}$ 区域的机位拍 摄频率较高, 而该区域属于实验区, 人类活动的干 扰可能会对黑鹿的生存产生威胁, 因此今后需要重 点加强该区域的监测, 以更好保护这一濒危旗舰物 种。基于全国红外相机的监测数据来看, 这3种动物 同时居住在同一地区的情况较少, 仅见本研究区和 浙江古田山国家级自然保护区。那么这3种亲源关 系相近物种较低的共存率, 跟它们生态位的相似性 是否存在一定关系? 数量和分布占绝对优势的小 鹿对食物和空间资源的竞争是否会对毛冠鹿和黑 鹿构成压力? 这些是将来需要重点关注的问题。

本次调查记录到42种鸟类(附录2), 远远低于 保护区原记录的295种(刘信中, 2003; 程松林等, 2013a), 可能的原因是红外相机固定于距离地面 50-80 cm的树干上, 主要适用于拍摄地面活动的地 栖鸟类, 如鸡形目各科、雀形目冻科。因此, 今后 开展鸟类多样性专项调查时, 需增设相机的高度, 同时采用样线法和痕迹调查法来弥补红外相机调 查技术的不足, 以便对保护区的鸟类进行全面清查 (Seki, 2010)。雉类是典型的森林地栖鸟类, 其生存 状况在一定程度上可反映当地森林的质量与保护 状况(张正旺等, 2003)。本次调查记录到 5 种雉类, 对 比保护区记录的7种雉类(程松林等, 2009), 缺少雉 鸡(Phasianus colchicus)和白颈长尾雉。这可能与相 机所处的位点没有覆盖到它们的种群分布范围有 关。所有记录的鸟类中, 白酠的RAI及相机位点率 在鸟类中居第一, 黄腹角雉居第四, 这一方面表明 保护区内这两种鸟类资源丰富、保护状态良好; 另
一方面表明两种鸟类的生态位相似, 而它们是如何 共存的值得深入研究。

本研究中兽类和林下鸟类群落多样性沿海拔 梯度呈现先增高、后下降的规律, 即中海拔段 (800-1,200 m)物种的种类和数量最为丰富(表1), 属 于多样性垂直分布格局中的中峰模式。这与何百锁 等(2016)在长青国家级自然保护区、刘芳等(2012) 在北京松山国家级自然保护区的调查结果相同。这 种模式符合生态学的中域效应假说 (mid-domain effect hypothesis)。该假说认为边界对物种分布施加 一定限制, 使边界附近的物种分布重叠较少, 中域 的物种的重叠程度较大, 导致物种丰富度从边界向 中心逐渐增加的分布格局(Colwell \& Lees, 2000; 王襄平等, 2009), 具体到海拔维度上, 则会在中等 海拔段物种多样性最高。本研究中中峰模式的形成 归于自然条件和人类因素共同造成。低于 $800 \mathrm{~m}$ 的 区域动物多样性较低主要是该海拔段的人为活动 多、干扰大; 植被主要是毛竹林, 群落结构单一, 竹 林密度大, 动物的活动空间受限, 且食物来源少。 中海拔段无人居住, 干扰小; 植被主要是常绿阔叶 林、常绿落叶阔叶混交林和针阔混交林, 林内植物 丰富, 动物可食用的资源较多, 生境多样性高, 适 宜动物栖息, 从而物种多样性较高。高于 $1,800 \mathrm{~m}$ 海 拔段受气候因子限制, 温度较低, 湿度较大; 植被 主要是灌从与草甸, 动物多样性低。另外, 物种数、 相对多度指数与多样性指数在不同功能区表现不 同, 核心区中红外相机拍摄的物种数最多, 但缓冲 区相对多度指数最高, 实验区的多样性最高(表1), 说明武夷山保护区核心区外围的兽类和鸟类物种 多度与多样性并不低, 而这些区域又是人为活动 多、干扰大的区域, 因此需要加强对缓冲区和实验 区的管护和监测。

本研究初步掌握了江西武夷山地面活动的大 型兽类和鸟类的物种组成、相对丰富度和空间分布 范围, 发现该保护区拥有较高的动物多样性, 是诸 多珍稀濒危兽类和鸟类的重要分布区, 结果为保护 区野生动物红外相机的长期监测提供了重要基础 资料。未来的工作重点可以侧重于利用红外相机对 目标动物的密度估算、空间分布研究和动物行为特 征的研究, 如鹿科动物的生活节律比较, 地栖鸟类 的筑巢育幼行为等。同时建议今后采用全国统一的 空间尺度抽样法, 如公里网格抽样法设置红外相机 
监测位点(肖治术等, 2014), 进一步增设相机位点并 扩大监测范围, 长期持续监测, 实现对整个保护区 野生动物资源的全方位调查。

致谢: 本次调查得到了江西武夷山国家级自然保 护区管理局的高度重视与大力支持, 程松林高级工 程师对方案给予了悉心指导, 刘江南调研员、祝于 红调研员和郑元庆、程林、艾亮、周亮、郑阳平等 参与了大量的野外调查工作。江西农业大学林学本 科生金庆梅、詹慧秀、公玮、熊思怡协助整理照片, 江西农业大学张微微副教授、徐永涛博士、应钦老 师帮助指导物种的识别, 在此一并表示感谢。

\section{ORCID}

杨清培 (D) https://orcid.org/0000-0002-9432-5898

宋庆妮 (D) https://orcid.org/0000-0002-3839-6587

\section{参考文献}

Chen SW, Yu JP, Chen XN, Shen XL, Li S, Ma KP (2016) Camera-trapping survey on the diversity of mammal and pheasant species in Gutianshan National Nature Reserve, Zhejiang Province. Acta Theriologica Sinica, 36, 292-301. (in Chinese with English abstract) [陈声文, 余建平, 陈小 南, 申小莉, 李晟, 马克平 (2016) 利用红外相机网络调 查古田山自然保护区的兽类及雉类多样性. 兽类学报, 36, 292-301.]

Cheng SL, Fang Y, Cheng L, Zhong ZY, Zheng YQ, Wang XM, Cheng YJ (2009) Pheasants and their conservation status in Wuyishan National Nature Reserve in Jiangxi Province. Journal of Hainan Normal University (Natural Science), 22, 83-85. (in Chinese with English abstract) [程 松林, 方毅, 程林, 钟志宇, 郑元庆, 王小民, 程义杰 (2009) 江西武夷山自然保护区的雉类资源及其保护. 海 南师范大学学报(自然科学版), 22, 83-85.]

Cheng SL, Mao YX, Hu EY, Lei P, Yuan RB, Zou SC (2017) Population biology and altitudinal distribution of Tragopan caboti in Jiangxi Wuyishan Nature Reserve. Scientia Silvae Sinicae, 53(10), 160-167. (in Chinese with English abstract) [程松林, 毛夷仙, 胡尔夷, 雷平, 袁荣斌, 邹思成 (2017) 江西武夷山自然保护区黄腹角雉种群生物学及海拔分布 特征. 林业科学, 53(10), 160-167.]

Cheng SL, Wu SY, Zhong ZY, Mao YX (2013a) Supplement of animals list in Jiangxi Wuyishan National Nature Reserve. Jiangxi Forestry Science and Technology, (2), 40-43, 52. (in Chinese with English abstract) [程松林, 吴 淑玉, 钟志宇, 毛夷仙 (2013a) 江西武夷山国家级自然 保护区动物名录增补. 江西林业科技, (2), 40-43, 52.]

Cheng SL, Yuan RB, Zou SC (2013b) Black muntjac
(Muntiacus crinifrons) found at Jiangxi Wuyishan. Acta Theriologica Sinica, 33, 94, 93. (in Chinese) [程松林, 袁荣 斌, 邹思成 (2013b) 江西武夷山发现黑麇. 兽类学报, 33, 94, 93.]

Colwell RK, Lees DC (2000) The mid-domain effect: Geometric constraints on the geography of species richness. Trends in Ecology and Evolution, 15, 70-76.

Frey S, Fisher JT, Burton AC, Volpe JP (2017) Investigating animal activity patterns and temporal niche partitioning using camera-trap data: Challenges and opportunities. Remote Sensing in Ecology and Conservation, 3, 123-132.

He BS, Sun RQ, Chen P, Dong W, Wang J, Wang DJ, Li S (2016) Baseline survey of mammal and bird diversity using camera-trapping in the Changqing National Nature Reserve of Shaanxi Province. Acta Theriologica Sinica, 36, 348-356. (in Chinese with English abstract) [何百锁, 孙瑞谦, 陈鹏, 董伟, 王军, 王大军, 李晟 (2016) 基于红外相机技术调 查长青国家级自然保护区兽类和鸟类多样性. 兽类学报, 36, 348-356.]

Jiang ZG, Ma Y, Wu Y, Wang YX (2015) China’s Mammal Diversity and Geographic Distribution. Science Press, Beijing. (in Chinese) [蒋志刚, 马勇, 吴毅, 王应祥 (2015) 中国哺乳动物多样性及地理分布. 科学出版社, 北京.]

Li GL, Li DQ, Xue YD, Wang XL, Yang JY, Yu HL (2014) Distribution of wildlife surveyed with infra-red cameras in the Shennongjia National Nature Reserve. Scientia Silvae Sinicae, 50(9), 97-104. (in Chinese with English abstract) [李广良, 李迪强, 薛亚东, 王秀磊, 杨敬元, 余辉亮 (2014) 利用红外相机研究神农架自然保护区野生动物分 布规律. 林业科学, 50(9), 97-104.]

Li S, Wang DJ, Xiao ZS, Li XH, Wang TM, Feng LM, Wang $Y$ (2014) Camera-trapping in wildlife research and conservation in China: Review and outlook. Biodiversity Science, 22, 685-695. (in Chinese with English abstract) [李 晟, 王大军, 肖治术, 李欣海, 王天明, 冯利民, 王云 (2014) 红外相机技术在我国野生动物研究与保护中的应 用与前景. 生物多样性, 22, 685-695.]

Liu F, Li DQ, Wu JG (2012) Using infra-red cameras to survey wildlife in Beijing Songshan National Nature Reserve. Acta Ecologica Sinica, 32, 730-739. (in Chinese with English abstract) [刘芳, 李迪强, 吴记贵 (2012) 利用红外相机调 查北京松山国家级自然保护区的野生动物物种. 生态学 报, 32, 730-739.]

Liu XZ (2003) Scientific Survey of the Wuyishan Nature Reserve in Jiangxi. Science Press, Beijing. (in Chinese) [刘 信中 (2003) 江西武夷山自然保护区科学考察集. 科学 出版社, 北京.]

Ma KP (2015) Species Catalogue of China: A remarkable achievement in the field of biodiversity science in China. Biodiversity Science, 23, 137-138. (in Chinese) [马克平 (2015) 中国生物多样性编目取得重要进展. 生物多样性, 23, 137-138.]

Seki SI (2010) Camera-trapping at artificial bathing sites 
provides a snapshot of a forest bird community. Journal of Forest Research, 15, 307-315.

Wang C, Zhou DQ, Liang S, Su HJ, Hu CS, Zhang MM (2019) Camera-trapping survey on mammals and birds in Guizhou Chishui Alsophila National Nature Reserve. Biodiversity Science, 27, 1147-1152. (in Chinese with English abstract) [王丞, 周大庆, 梁盛, 粟海军, 胡灿实, 张明明 (2019) 贵州赤水杪椤国家级自然保护区鸟兽多样性红外相机初 步监测. 生物多样性, 27, 1147-1152.]

Wang GH, Li SQ, Shi ZP, Wang SN, Ye JP, Zhou QH (2016) Preliminary survey of mammal and bird diversity of Guangxi Maoershan National Nature Reserve-Based on infrared camera monitoring. Acta Theriologica Sinica, 36, 338-347. (in Chinese with English abstract) [汪国海, 李生 强, 施泽攀, 王绍能, 叶建平, 周岐海 (2016) 广西猫儿 山自然保护区的兽类和鸟类多样性初步调查一一基于红 外相机监测数据. 兽类学报, 36, 338-347.]

Wang XP, Fang JY, Tang ZY (2009) The mid-domain effect hypothesis: Models, evidence and limitations. Biodiversity Science, 17, 568-578. (in Chinese with English abstract) [王 襄平, 方精云, 唐志尧 (2009) 中域效应假说: 模型、证 据和局限性. 生物多样性, 17, 568-578.]

Xiao ZS (2016) Wildlife resource inventory using camera trapping in natural reserves in China. Acta Theriologica Sinica, 36, 270-271. (in Chinese) [肖治术 (2016) 红外相 机技术促进我国自然保护区野生动物资源编目调查. 兽 类学报, 36, 270-271.]

Xiao ZS, Li XH, Wang XZ, Zhou QH, Quan RC, Shen XL, Li S (2014) Developing camera-trapping protocols for wildlife monitoring in Chinese forests. Biodiversity Science, 22, 704-711. (in Chinese with English abstract) [肖治术, 李欣 海, 王学志, 周岐海, 权锐昌, 申小莉, 李晟 (2014) 探 讨我国森林野生动物红外相机监测规范. 生物多样性, 22, 704-711.]

Zhang ZW, Ding CQ, Ding P, Zheng GM (2003) The current status and a conservation strategy for species of Galliformes in China. Biodiversity Science, 11, 414-421. (in Chinese with English abstract) [张正旺, 丁长青, 丁平, 郑光美 (2003) 中国鸡形目鸟类的现状与保护对策. 生物多样性, 11, 414-421.]

Zheng GM (2017) Checklist on the Classification and Distribution of the Birds of China, 3rd edn. Science Press, Beijing. (in Chinese) [郑光美 (2017) 中国鸟类分类与分 布名录(第三版). 科学出版社, 北京.]

(责任编委: 蒋学龙 责任编辑: 间文杰)

\section{附录 Supplementary Material}

\section{附录1 江西武夷山国家级自然保护区红外相机布设位点信息}

Appendix 1 Stations information of infra-red camera-traps in the Jiangxi Wuyishan National Nature Reserve https://www.biodiversity-science.net/fileup/PDF/2020307-1.pdf

附录2 江西武夷山国家级自然保护区红外相机记录的兽类和鸟类名录

Appendix 2 List of mammal and bird species recorded by infra-red camera-traps in the Jiangxi Wuyishan National Nature Reserve https://www.biodiversity-science.net/fileup/PDF/2020307-2.pdf

附录3 江西武夷山国家级自然保护区红外相机拍摄的主要鸟类和兽类照片

Appendix 3 Important mammals and birds recorded by the infra-red camera-traps in the Jiangxi Wuyishan National Nature Reserve https://www.biodiversity-science.net/fileup/PDF/2020307-3.pdf 
郭英荣, 兰文军, 邹思成, 袁荣斌, 董晓雨, 曹吉锐, 杨清培, 宋庆妮 (2021) 江西武夷山国家级自然保护区林下鸟类和兽类 资源的红外相机监测. 生物多样性, 29, 811-818. https://www.biodiversity-science.net/CN/10.17520/biods.2020307

附录1 江西武夷山国家级自然保护区红外相机布设位点信息

Appendix 1 Stations information of infra-red camera-traps in the Jiangxi Wuyishan National Nature Reserve

\begin{tabular}{|c|c|c|c|c|c|c|}
\hline $\begin{array}{l}\text { 相机号 } \\
\text { Camera } \\
\text { code }\end{array}$ & $\begin{array}{l}\text { 东经 } \\
\text { Longitude } \\
\text { (E) }\end{array}$ & $\begin{array}{l}\text { 北纬 Latitude } \\
(\mathrm{N})\end{array}$ & $\begin{array}{l}\text { 海拔 } \\
\text { Elevation } \\
(\mathrm{m})\end{array}$ & $\begin{array}{l}\text { 相机工作日 } \\
\text { Camera days }\end{array}$ & $\begin{array}{l}\text { 独立照片数 } \\
\text { No. of } \\
\text { independent } \\
\text { photographs }\end{array}$ & $\begin{array}{l}\text { 物种数 No. } \\
\text { of species }\end{array}$ \\
\hline 1 & $117^{\circ} 53^{\prime}$ & $27^{\circ} 59^{\prime}$ & 531 & 293 & 86 & 7 \\
\hline 2 & $117^{\circ} 53^{\prime}$ & $27^{\circ} 59^{\prime}$ & 804 & 284 & 443 & 19 \\
\hline 3 & $117^{\circ} 53^{\prime}$ & $27^{\circ} 59^{\prime}$ & 1,001 & 397 & 204 & 18 \\
\hline 4 & $117^{\circ} 50^{\prime}$ & $27^{\circ} 58^{\prime}$ & 1,175 & 582 & 88 & 19 \\
\hline 5 & $117^{\circ} 50^{\prime}$ & $27^{\circ} 57^{\prime}$ & 946 & 457 & 153 & 19 \\
\hline 6 & $117^{\circ} 50^{\prime}$ & $27^{\circ} 58^{\prime}$ & 1,122 & 630 & 444 & 29 \\
\hline 7 & $117^{\circ} 50^{\prime}$ & $27^{\circ} 58^{\prime}$ & 998 & 407 & 274 & 21 \\
\hline 8 & $117^{\circ} 50^{\prime}$ & $27^{\circ} 58^{\prime}$ & 952 & 582 & 178 & 22 \\
\hline 9 & $117^{\circ} 50^{\prime}$ & $27^{\circ} 58^{\prime}$ & 808 & 280 & 77 & 6 \\
\hline 10 & $117^{\circ} 47^{\prime}$ & $27^{\circ} 56^{\prime}$ & 698 & 576 & 150 & 9 \\
\hline 11 & $117^{\circ} 47^{\prime}$ & $27^{\circ} 56^{\prime}$ & 930 & 581 & 462 & 18 \\
\hline 12 & $117^{\circ} 47^{\prime}$ & $27^{\circ} 55^{\prime}$ & 1,217 & 322 & 66 & 12 \\
\hline 13 & $117^{\circ} 46^{\prime}$ & $27^{\circ} 55^{\prime}$ & 781 & 250 & 23 & 11 \\
\hline 14 & $117^{\circ} 46^{\prime}$ & $27^{\circ} 54^{\prime}$ & 976 & 578 & 144 & 7 \\
\hline 15 & $117^{\circ} 47^{\prime}$ & $27^{\circ} 54^{\prime}$ & 1,128 & 332 & 51 & 11 \\
\hline 16 & $117^{\circ} 46^{\prime}$ & $27^{\circ} 51^{\prime}$ & 2,051 & 261 & 32 & 3 \\
\hline 17 & $117^{\circ} 46^{\prime}$ & $27^{\circ} 52^{\prime}$ & 2,009 & 463 & 226 & 12 \\
\hline 18 & $117^{\circ} 46^{\prime}$ & $27^{\circ} 52^{\prime}$ & 1,621 & 263 & 1 & 1 \\
\hline 19 & $117^{\circ} 46^{\prime}$ & $27^{\circ} 53^{\prime}$ & 1,328 & 343 & 128 & 7 \\
\hline 20 & $117^{\circ} 45^{\prime}$ & $27^{\circ} 53^{\prime}$ & 1,079 & 454 & 575 & 12 \\
\hline 21 & $117^{\circ} 45^{\prime}$ & $27^{\circ} 50^{\prime}$ & 1,565 & 307 & 33 & 5 \\
\hline 22 & $117^{\circ} 45^{\prime}$ & $27^{\circ} 51^{\prime}$ & 1,306 & 296 & 22 & 5 \\
\hline 23 & $117^{\circ} 44^{\prime}$ & $27^{\circ} 51^{\prime}$ & 1,076 & 296 & 16 & 5 \\
\hline 24 & $117^{\circ} 44^{\prime}$ & $27^{\circ} 51^{\prime}$ & 876 & 289 & 46 & 7 \\
\hline 25 & $117^{\circ} 45^{\prime}$ & $27^{\circ} 50^{\prime}$ & 1,870 & 236 & 192 & 12 \\
\hline 26 & $117^{\circ} 44^{\prime}$ & $27^{\circ} 49^{\prime}$ & 1,725 & 266 & 21 & 6 \\
\hline 27 & $117^{\circ} 44^{\prime}$ & $27^{\circ} 49^{\prime}$ & 1,522 & 403 & 295 & 13 \\
\hline 28 & $117^{\circ} 44^{\prime}$ & $27^{\circ} 49^{\prime}$ & 1,420 & 387 & 232 & 16 \\
\hline 29 & $117^{\circ} 43^{\prime}$ & $27^{\circ} 49^{\prime}$ & 1,260 & 284 & 27 & 6 \\
\hline 30 & $117^{\circ} 43^{\prime}$ & $27^{\circ} 49^{\prime}$ & 1,360 & 284 & 25 & 4 \\
\hline 31 & $117^{\circ} 42^{\prime}$ & $27^{\circ} 52^{\prime}$ & 1,135 & 306 & 232 & 7 \\
\hline 32 & $117^{\circ} 42^{\prime}$ & $27^{\circ} 53^{\prime}$ & 1,361 & 332 & 300 & 17 \\
\hline 33 & $117^{\circ} 42^{\prime}$ & $27^{\circ} 53^{\prime}$ & 1,423 & 361 & 316 & 23 \\
\hline 34 & $117^{\circ} 42^{\prime}$ & $27^{\circ} 53^{\prime}$ & 1,645 & 371 & 230 & 13 \\
\hline 35 & $117^{\circ} 42^{\prime}$ & $27^{\circ} 53^{\prime}$ & 1,886 & 183 & 199 & 6 \\
\hline 36 & $117^{\circ} 42^{\prime}$ & $27^{\circ} 53^{\prime}$ & 2,000 & 234 & 26 & 7 \\
\hline 37 & $117^{\circ} 42^{\prime}$ & $27^{\circ} 50^{\prime}$ & 1,762 & 436 & 159 & 17 \\
\hline 38 & $117^{\circ} 42^{\prime}$ & $27^{\circ} 50^{\prime}$ & 1,664 & 196 & 89 & 13 \\
\hline
\end{tabular}


郭英荣, 兰文军, 邹思成, 袁荣斌, 董晓雨, 曹吉锐, 杨清培, 宋庆妮 (2021) 江西武夷山国家级自然保护区林下鸟类和兽类 资源的红外相机监测. 生物多样性, 29, 811-818. https://www.biodiversity-science.net/CN/10.17520/biods.2020307

\begin{tabular}{lllllll}
\hline $\begin{array}{l}\text { 相机号 } \\
\text { Camera } \\
\text { code }\end{array}$ & $\begin{array}{l}\text { Longitude } \\
\text { (E) }\end{array}$ & $\begin{array}{l}\text { 北纬 Latitude } \\
(\mathrm{N})\end{array}$ & $\begin{array}{l}\text { 海拔 } \\
\text { Elevation } \\
(\mathrm{m})\end{array}$ & $\begin{array}{l}\text { 相机工作日 } \\
\text { Camera days }\end{array}$ & $\begin{array}{l}\text { 独立照片数 } \\
\text { No. of } \\
\text { independent } \\
\text { photographs }\end{array}$ & $\begin{array}{l}\text { 物种数 No. } \\
\text { of species }\end{array}$ \\
\hline 39 & $117^{\circ} 42^{\prime}$ & $27^{\circ} 51^{\prime}$ & 1,576 & 273 & 164 & 14 \\
40 & $117^{\circ} 42^{\prime}$ & $27^{\circ} 51^{\prime}$ & 1,372 & 206 & 421 & 8 \\
41 & $117^{\circ} 43^{\prime}$ & $27^{\circ} 51^{\prime}$ & 1,131 & 371 & 70 & 7 \\
42 & $117^{\circ} 42^{\prime}$ & $27^{\circ} 51^{\prime}$ & 1,325 & 280 & 111 & 15 \\
43 & $117^{\circ} 42^{\prime}$ & $27^{\circ} 49^{\prime}$ & 1,242 & 521 & 195 & 8 \\
44 & $117^{\circ} 42^{\prime}$ & $27^{\circ} 49^{\prime}$ & 1,504 & 300 & 119 & 8 \\
45 & $117^{\circ} 42^{\prime}$ & $27^{\circ} 49^{\prime}$ & 1,696 & 573 & 173 & 10 \\
46 & $117^{\circ} 42^{\prime}$ & $27^{\circ} 50^{\prime}$ & 1,778 & 383 & 62 & 6 \\
47 & $117^{\circ} 41^{\prime}$ & $27^{\circ} 50^{\prime}$ & 1,176 & 263 & 79 & 9 \\
48 & $117^{\circ} 41^{\prime}$ & $27^{\circ} 51^{\prime}$ & 1,456 & 245 & 15 & 3 \\
49 & $117^{\circ} 40^{\prime}$ & $27^{\circ} 51^{\prime}$ & 746 & 256 & 314 & 15 \\
50 & $117^{\circ} 40^{\prime}$ & $27^{\circ} 50^{\prime}$ & 998 & 256 & 249 & 10 \\
51 & $117^{\circ} 40^{\prime}$ & $27^{\circ} 50^{\prime}$ & 1,084 & 355 & 412 & 20 \\
52 & $117^{\circ} 40^{\prime}$ & $27^{\circ} 50^{\prime}$ & 1,284 & 333 & 259 & 14 \\
\hline
\end{tabular}


郭英荣, 兰文军, 邹思成, 袁荣斌, 董晓雨, 曹吉锐, 杨清培, 宋庆妮 (2021) 江西武夷山国家级自然保护区林下鸟类和兽类 资源的红外相机监测. 生物多样性, 29, 811-818. https://www.biodiversity-science.net/CN/10.17520/biods.2020307

附录2 江西武夷山国家级自然保护区红外相机记录的兽类和鸟类名录

Appendix 2 List of mammal and bird species recorded by infra-red camera-traps in the Jiangxi Wuyishan National Nature Reserve

\begin{tabular}{|c|c|c|c|c|c|c|c|}
\hline 物种 Species & $\begin{array}{l}\text { 国家保 } \\
\text { 护级别 } \\
\text { Protected } \\
\text { category }\end{array}$ & $\begin{array}{l}\text { CITES附 } \\
\text { 录 CITES } \\
\text { Appendix }\end{array}$ & $\begin{array}{l}\text { IUCN } \\
\text { 红色 } \\
\text { 名录 } \\
\text { 级别 } \\
\text { IUCN } \\
\text { Red } \\
\text { List }\end{array}$ & $\begin{array}{l}\text { 中国物 } \\
\text { 种红色 } \\
\text { 名录 } \\
\text { China } \\
\text { Species } \\
\text { Red List }\end{array}$ & $\begin{array}{l}\text { 独立照片数 } \\
\text { No. of } \\
\text { independent } \\
\text { photographs }\end{array}$ & $\begin{array}{l}\text { 位点数及 } \\
\text { 比例 No. } \\
\text { of stations } \\
(\%)\end{array}$ & $\begin{array}{l}\text { 相对多度指数 } \\
\text { Relative } \\
\text { abundance } \\
\text { index (RAI) }\end{array}$ \\
\hline
\end{tabular}

\section{哺乳纲 Mammalia}

\section{灵长目 Primates}

猴科 Cercopithecidae

1. 藏酋猴 Macaca thibetana*

II

II

NT

LC

761

43(82.7)

41.32

\section{啮齿目 Rodentia}

豪猪科 Hystricidae

2. 中国豪猪 Hystrix hodgsoni

LC

$$
\text { LC }
$$

3

松鼠科 Sciuridae

3. 赤腹松鼠 Callosciurus erythraeus

$\begin{array}{lll}\text { LC } & \text { LC } & 50 \\ \text { LC } & \text { LC } & 48 \\ \text { LC } & \text { LC } & 9\end{array}$

16(30.8) $\quad 2.71$

4. 珀氏长吻松鼠 Dremomys pernyi

LC LC

9

15(28.8)

2.61

5. 隐花纹松鼠 Tamiops swinhoei

鼠科 Muridae

6. 鼠 Small rodents

\section{兔形目 Lagomorpha}

兔科 Leporidae

7. 华南兔 Lepus sinensis

LC

LC

362

14(26.9)

19.66

\section{食肉目 Carnivora}

灵猫科 Viverridae

8. 花面狸 Paguma larvata

LC

II

LC

II

10. 黄喉貂 Martes flavigula

LC NT

42(80.7)

71.46

犬科 Canidae

9. 赤狐 Vulpes vulpes

I

NT

42

11(21.1)

11. 黄鼠 Mustela sibirica

LC NT

10

15(28.8) $\quad 1.68$

12. 黄腹鼠 Mustela kathiah

13. 猪獾 Arctonyx collaris

NT NT

167

$6(11.5) \quad 0.54$

VU VU

59

19(36.5) $\quad 9.07$

獴科 Herpestidae

14. 食蟹獴 Herpestes urva

LC

NT

7

2(3.8)

0.39

熊科 Ursidae

15. 亚洲黑熊 Ursus thibetanus

II

VU

VU

23

14(26.9)

\section{偶蹄目 Artiodactyla}

猪科 Suidae

16. 野猪 Sus scrofa

LC LC

392

37(71.1) 
郭英荣, 兰文军, 邹思成, 袁荣斌, 董晓雨, 曹吉锐, 杨清培, 宋庆妮 (2021) 江西武夷山国家级自然保护区林下鸟类和兽类 资源的红外相机监测. 生物多样性, 29, 811-818. https://www.biodiversity-science.net/CN/10.17520/biods.2020307

\begin{tabular}{|c|c|c|c|c|c|c|}
\hline $\begin{array}{l}\text { 国家保 } \\
\text { 护级别 } \\
\text { Protected } \\
\text { category }\end{array}$ & $\begin{array}{l}\text { CITES附 } \\
\text { 录 CITES } \\
\text { Appendix }\end{array}$ & $\begin{array}{l}\text { IUCN } \\
\text { 红色 } \\
\text { 名录 } \\
\text { 级别 } \\
\text { IUCN } \\
\text { Red } \\
\text { List }\end{array}$ & $\begin{array}{l}\text { 中国物 } \\
\text { 种红色 } \\
\text { 名录 } \\
\text { China } \\
\text { Species } \\
\text { Red List }\end{array}$ & $\begin{array}{l}\text { 独立照片数 } \\
\text { No. of } \\
\text { independent } \\
\text { photographs }\end{array}$ & $\begin{array}{l}\text { 位点数及 } \\
\text { 比例 No. } \\
\text { of stations } \\
(\%)\end{array}$ & $\begin{array}{l}\text { 相对多度指数 } \\
\text { Relative } \\
\text { abundance } \\
\text { index (RAI) }\end{array}$ \\
\hline II & & NT & VU & 70 & $18(34.6)$ & 3.80 \\
\hline \multirow[t]{2}{*}{ I } & I & VU & EN & 38 & $10(19.2)$ & 2.06 \\
\hline & & $\mathrm{LC}$ & VU & 4130 & $49(94.2)$ & 224.20 \\
\hline II & I & NT & VU & 95 & $22(42.3)$ & 5.16 \\
\hline
\end{tabular}

\section{鸟纲 Aves}

\section{隼形目 Falconiformes}

鹰科 Accipitridae

21. 凤头鹰 Accipiter trivirgatus

22. 鹰雕 Spizaetus nipalensis

II II

$\begin{array}{lll}\text { LC } & \text { LC } & 1 \\ \text { LC } & \text { LC } & 1\end{array}$

$\begin{array}{ll}1(1.9) & 0.05 \\ 1(1.9) & 0.05\end{array}$

\section{鸡形目 Galliformes}

雉科 Phasianidae

23. 黄腹角雉 Tragopan caboti*

$\begin{array}{lll}\text { VU } & \text { VU } & 97 \\ \text { NT } & \text { VU } & 22 \\ \text { LC } & \text { LC } & 431 \\ \text { LC } & \text { NT } & 2 \\ \text { LC } & \text { LC } & 1\end{array}$

18(34.6)

5.27

24. 白眉山鹧鸪 Arborophila gingica*

25. 白闲 Lophura nycthemera

II

26. 勺鸡 Pucrasia macrolopha

$\mathrm{LC}$

27. 灰胸竹鸡 Bambusicola thoracicus*

\section{鸽形目 Columbiformes}

鸭鸽科 Columbidae

28. 山斑鸠 Streptopelia orientalis

LC LC 1

1(1.9)

0.06

\section{裂形目 Piciformes}

啄木乌科 Picidae

29. 黄嘴栗啄木鸟 Blythipicus pyrrhotis

LC LC 3

$3(5.8)$

0.16

30. 灰头绿豚木鸟 Picus canus

LC LC 9

$7(13.5)$

0.49

31. 竹啄木鸟 Gecinulus grantia

LC

$5(9.6)$

0.43

\section{雀形目 Passeriformes}

軠科 Pycnonotidae

32. 栗背短脚鹎 Hemixos castanonotus

33. 绿翅短脚烁 Hypsipetes mcclellandii

LC LC 6

2(3.8)

0.33

LC

LC

2(3.8)

0.22

伯劳科 Laniidae

34. 棕背伯劳 Lanius schach

$\mathrm{LC}$

$$
\text { LC }
$$

2

1(1.9)

卷尾科 Dicruridae

35. 黑卷尾 Dicrurus macrocercus

LC

$$
\text { LC }
$$

1(1.9)

鸦科 Corvidae
36. 灰树鹊 Dendrocitta formosae
37. 松鸦 Garrulus glandarius

$\begin{array}{lllll}\text { LC } & \text { LC } & 11 & 4(7.7) & 0.60 \\ \text { LC } & \text { LC } & 13 & 8(15.4) & 0.71\end{array}$


郭英荣, 兰文军, 邹思成, 袁荣斌, 董晓雨, 曹吉锐, 杨清培, 宋庆妮 (2021) 江西武夷山国家级自然保护区林下鸟类和兽类 资源的红外相机监测. 生物多样性, 29, 811-818. https://www.biodiversity-science.net/CN/10.17520/biods.2020307

\begin{tabular}{|c|c|c|c|c|c|c|c|}
\hline 物种 Species & $\begin{array}{l}\text { 国家保 } \\
\text { 护级别 } \\
\text { Protected } \\
\text { category }\end{array}$ & $\begin{array}{l}\text { CITES附 } \\
\text { 录 CITES } \\
\text { Appendix }\end{array}$ & $\begin{array}{l}\text { IUCN } \\
\text { 红色 } \\
\text { 名录 } \\
\text { 级别 } \\
\text { IUCN } \\
\text { Red } \\
\text { List }\end{array}$ & $\begin{array}{l}\text { 中国物 } \\
\text { 种红色 } \\
\text { 名录 } \\
\text { China } \\
\text { Species } \\
\text { Red List }\end{array}$ & $\begin{array}{l}\text { 独立照片数 } \\
\text { No. of } \\
\text { independent } \\
\text { photographs }\end{array}$ & $\begin{array}{l}\text { 位点数及 } \\
\text { 比例 No. } \\
\text { of stations } \\
(\%)\end{array}$ & $\begin{array}{l}\text { 相对多度指数 } \\
\text { Relative } \\
\text { abundance } \\
\text { index (RAI) }\end{array}$ \\
\hline 38. 紫啸冻 Myophonus caeruleus & & & $\mathrm{LC}$ & $\mathrm{LC}$ & 316 & $18(34.6)$ & 17.16 \\
\hline 39. 灰背冻 Turdus hortulorum & & & $\mathrm{LC}$ & LC & 1 & $1(1.9)$ & 0.05 \\
\hline 40. 白眉冻 Turdus obscurus & & & $\mathrm{LC}$ & $\mathrm{LC}$ & 4 & $1(1.9)$ & 0.22 \\
\hline 41. 白腹冻 Turdus pallidus & & & $\mathrm{LC}$ & $\mathrm{LC}$ & 1 & $1(1.9)$ & 0.05 \\
\hline 42. 虎斑地冻 Zoothera dauma & & & $\mathrm{LC}$ & $\mathrm{LC}$ & 13 & $5(9.6)$ & 0.05 \\
\hline 43. 光背地冻 Zoothera mollissima & & & $\mathrm{LC}$ & $\mathrm{LC}$ & 1 & $1(1.9)$ & 0.05 \\
\hline 44. 白眉地冻 Zoothera sibirica & & & $\mathrm{LC}$ & $\mathrm{LC}$ & 2 & $2(3.8)$ & 0.11 \\
\hline 45. 红胁蓝尾鸲 Tarsiger cyanurus & & & $\mathrm{LC}$ & $\mathrm{LC}$ & 25 & $9(17.3)$ & 1.36 \\
\hline \multicolumn{8}{|l|}{ 画眉科 Timaliidae } \\
\hline 46. 画眉 Garrulax canorus & & II & $\mathrm{LC}$ & NT & 1 & $1(1.9)$ & 0.05 \\
\hline 47. 灰翅噪鹛 Garrulax cineraceus & & & $\mathrm{LC}$ & $\mathrm{LC}$ & 29 & $6(11.5)$ & 1.58 \\
\hline 48. 小黑领噪鹋 Garrulax monileger & & & $\mathrm{LC}$ & $\mathrm{LC}$ & 7 & $5(9.6)$ & 0.38 \\
\hline 49. 黑领噪鸤 Garrulax pectoralis & & & $\mathrm{LC}$ & $\mathrm{LC}$ & 115 & $25(48.1)$ & 6.24 \\
\hline 50. 棕噪鹛 Garrulax poecilorhynchus* & & & $\mathrm{LC}$ & $\mathrm{LC}$ & 66 & $12(23.1)$ & 3.58 \\
\hline 51. 白项噪柅 Garrulax sannio & & & $\mathrm{LC}$ & $\mathrm{LC}$ & 1 & $1(1.9)$ & 0.05 \\
\hline 52. 斑胸钩嘴哃 Pomatorhinus erythrocnemis & & & $\mathrm{LC}$ & $\mathrm{LC}$ & 35 & $10(19.2)$ & 1.9 \\
\hline 53. 棕颈钩嘴鹛 Pomatorhinus ruficollis & & & $\mathrm{LC}$ & $\mathrm{LC}$ & 23 & $8(15.4)$ & 1.25 \\
\hline 54. 红嘴相思鸟 Leiothrix lutea & & II & $\mathrm{LC}$ & NT & 10 & $5(9.6)$ & 0.54 \\
\hline 55. 红头穗䴗 Stachyris ruficeps & & & $\mathrm{LC}$ & $\mathrm{LC}$ & 3 & $2(3.8)$ & 0.16 \\
\hline 56. 灰眀雀倜 Alcippe morrisonia & & & $\mathrm{LC}$ & $\mathrm{LC}$ & 1 & $1(1.9)$ & 0.05 \\
\hline \multicolumn{8}{|l|}{ 鸦雀科 Paradoxornithidae } \\
\hline 57. 灰头鸦雀 Paradoxornis gularis & & & $\mathrm{LC}$ & $\mathrm{LC}$ & 3 & $2(3.8)$ & 0.16 \\
\hline 58. 棕头鸦雀 Paradoxornis webbianus & & & $\mathrm{LC}$ & $\mathrm{LC}$ & 2 & $1(1.9)$ & 0.11 \\
\hline \multicolumn{8}{|l|}{ 蒀科 Sylviidae } \\
\hline 59. 极北柳莺 Phylloscopus borealis & & & $\mathrm{LC}$ & $\mathrm{LC}$ & 1 & $1(1.9)$ & 0.05 \\
\hline 60. 棕脸鹟莺 Abroscopus albogularis & & & $\mathrm{LC}$ & $\mathrm{LC}$ & 7 & $5(9.6)$ & 0.38 \\
\hline \multicolumn{8}{|l|}{ 绣眼鸟科 Zosteropidae } \\
\hline \multicolumn{8}{|l|}{ 山雀科 Paridae } \\
\hline 62. 黄项山雀 Parus spilonotus & & & $\mathrm{LC}$ & $\mathrm{LC}$ & 1 & $1(1.9)$ & 0.05 \\
\hline
\end{tabular}

因物种鉴定困难，鼠科物种的独立照片数和相对多度指数均合并统计。EN：濒危; VU: 易危; NT: 近危; LC: 无危。*中国特有种。

Mice were not identified into species. EN, Endangered; VU, Vulnerable; NT, Near Threatened; LC, Least Concern. * Endemic Species of China. 
郭英荣, 兰文军, 邹思成, 袁荣斌, 董晓雨, 曹吉锐, 杨清培, 宋庆妮 (2021) 江西武夷山国家级自然保护区林下鸟类和兽类 资源的红外相机监测. 生物多样性, 29, 811-818. https://www.biodiversity-science.net/CN/10.17520/biods.2020307

附录3 江西武夷山国家级自然保护区红外相机拍摄的主要鸟类和兽类照片

Appendix 3 Important mammals and birds recorded by the infra-red camera-traps in the Jiangxi Wuyishan National Nature Reserve

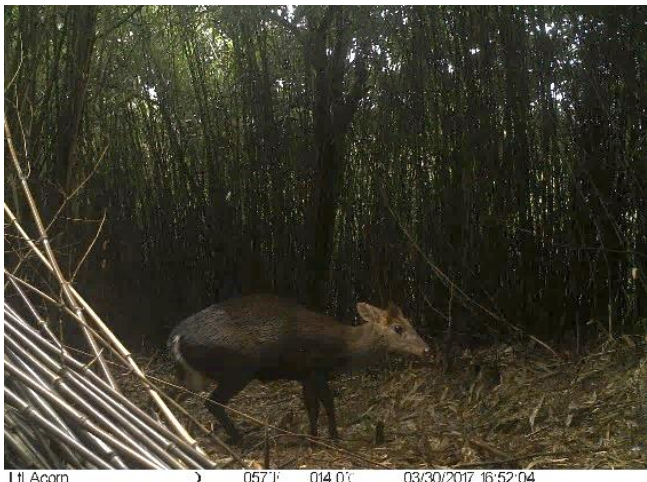

黑鹿 Muntiacus crinifrons

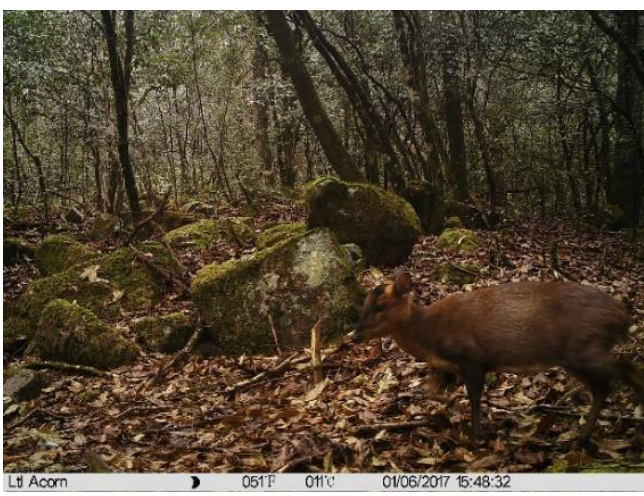

小鹿 Muntiacus reevesi

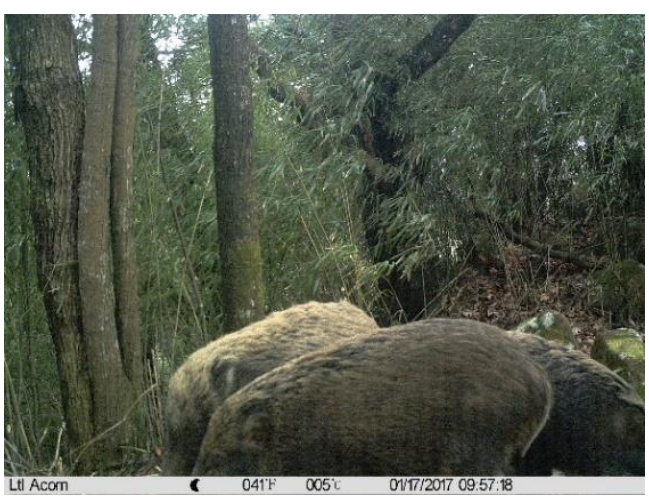

野猪 Sus scrofa

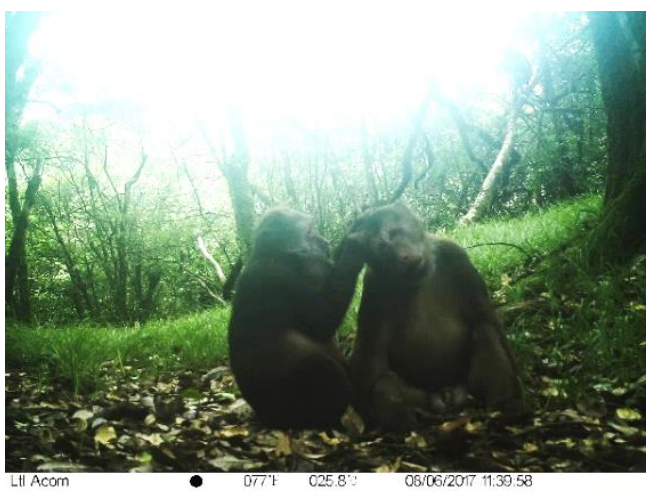

藏酋猴 Macaca thibetana

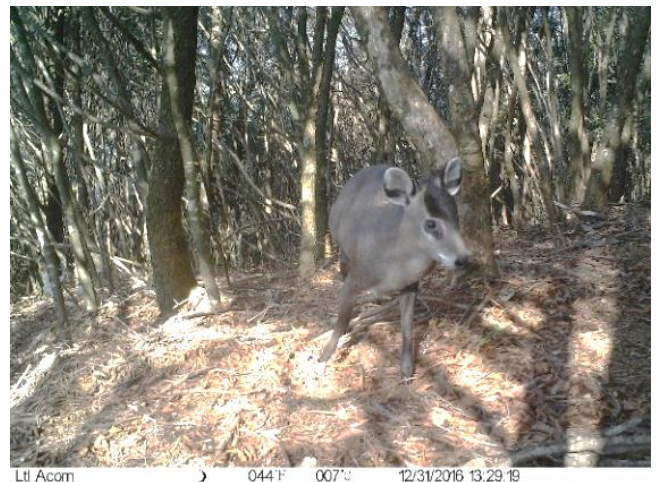

毛冠鹿 Elaphodus cephalophus

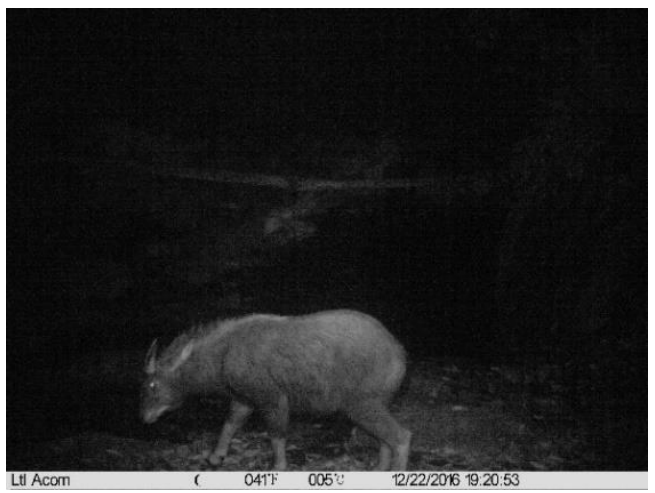

中华镾羚 Capricornis milneedwardsii

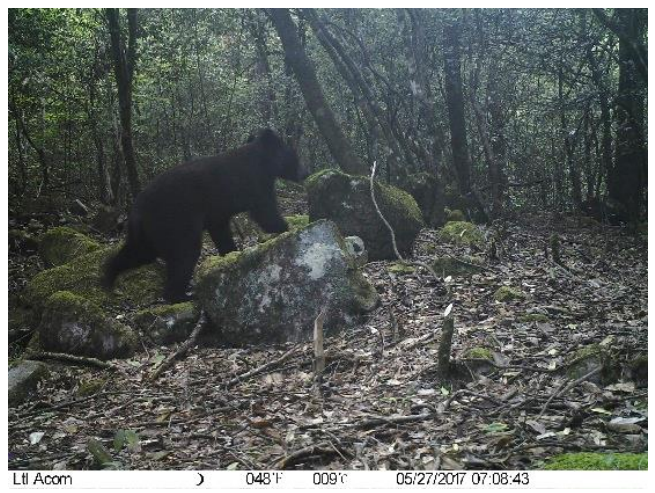

亚洲黑熊 Ursus thibetanus

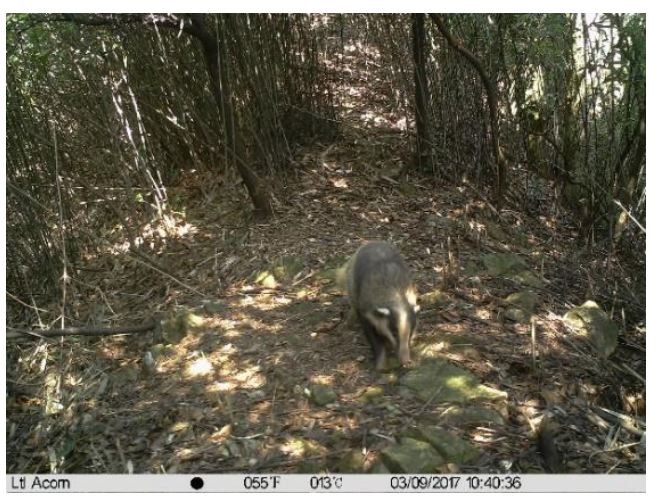

猪獾 Arctonyx collaris 
郭英荣, 兰文军, 邹思成, 袁荣斌, 董晓雨, 曹吉锐, 杨清培, 宋庆妮 (2021) 江西武夷山国家级自然保护区林下鸟类和兽类 资源的红外相机监测. 生物多样性, 29, 811-818. https://www.biodiversity-science.net/CN/10.17520/biods.2020307

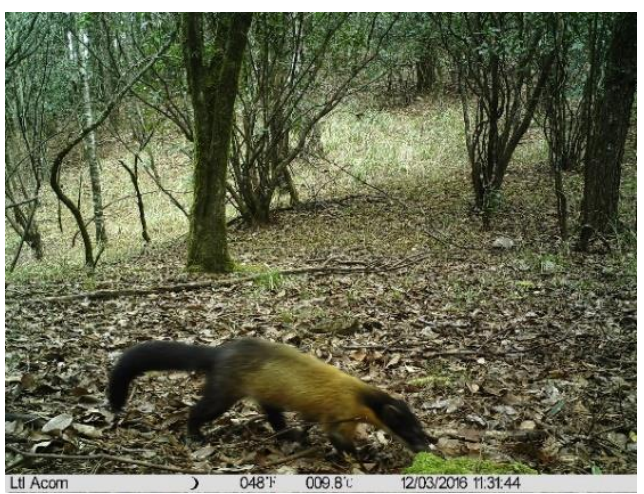

黄喉貂 Martes flavigula

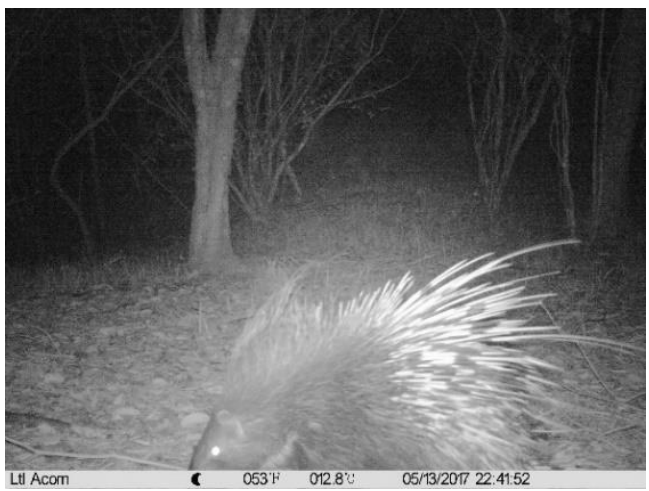

豪猪 Hystrix hodgsoni

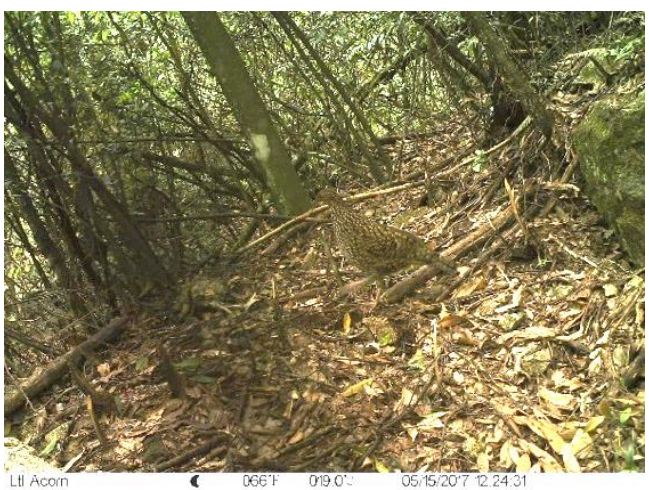

黄腹角雉 Tragopan caboti ㅇ

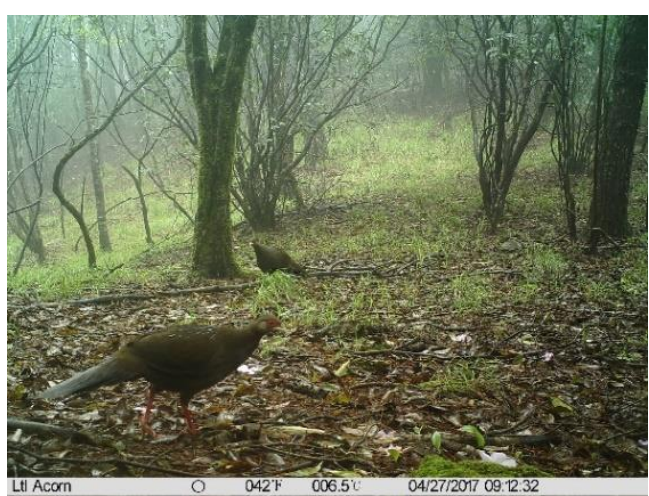

白㜀 Lophura nycthemera 우

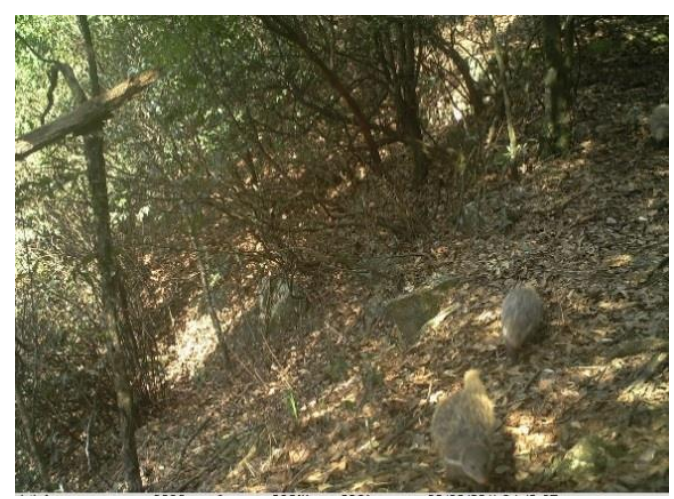

食蟹獴 Herpestes urva

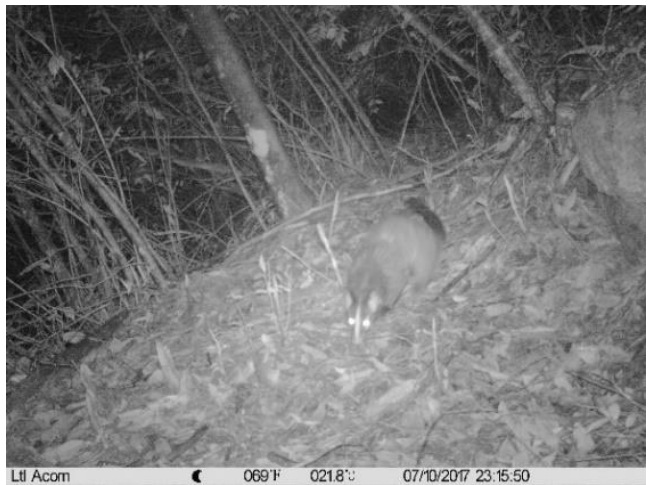

花面狸 Paguma larvata

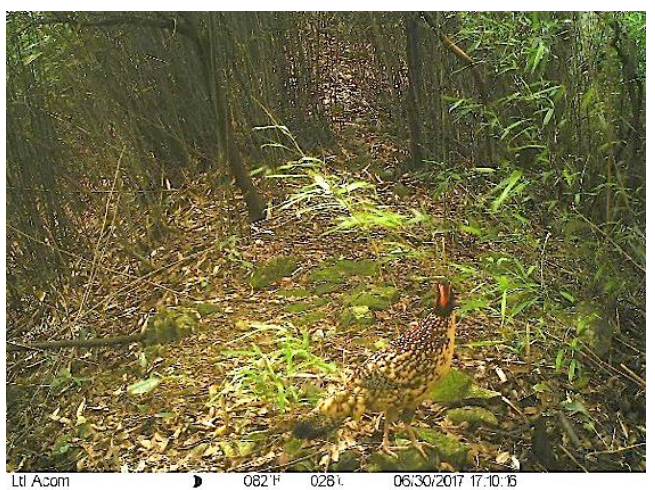

黄腹角雉 $T$. caboti $\precsim$

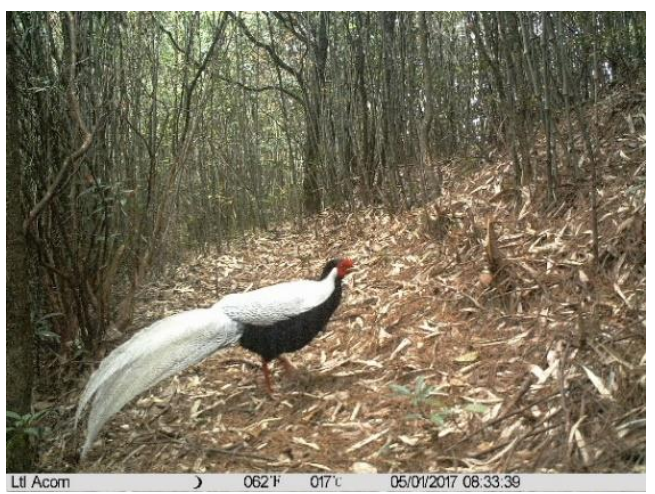

白鹇 Lophura nycthemera $\widehat{\partial}$ 
郭英荣, 兰文军, 邹思成, 袁荣斌, 董晓雨, 曹吉锐, 杨清培, 宋庆妮 (2021) 江西武夷山国家级自然保护区林下鸟类和兽类 资源的红外相机监测. 生物多样性, 29, 811-818. https://www.biodiversity-science.net/CN/10.17520/biods.2020307

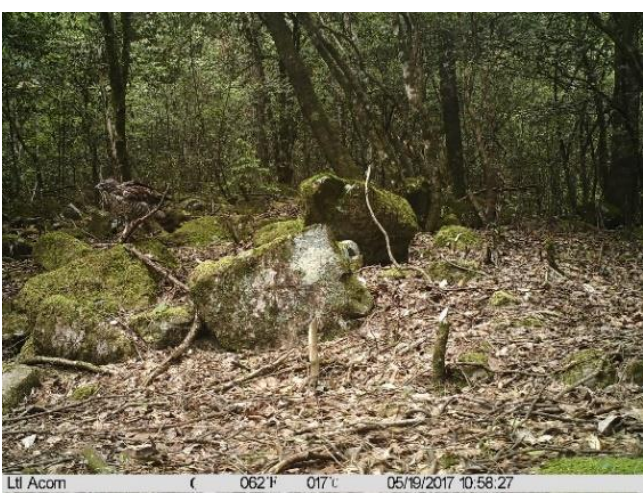

鹰雕 Spizaetus nipalensis

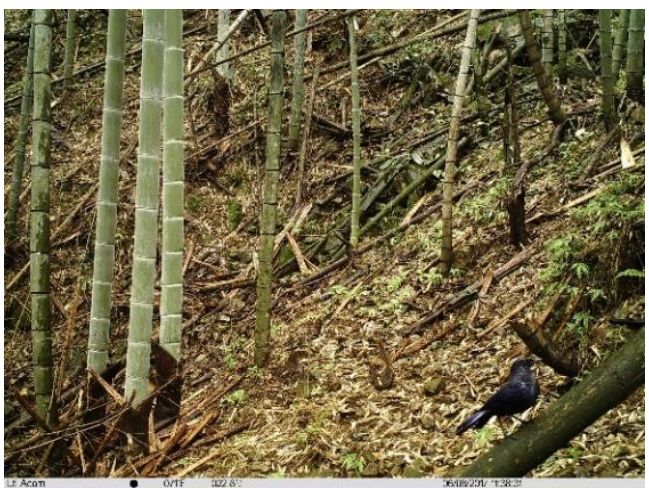

紫啸冻 Myophonus caeruleus

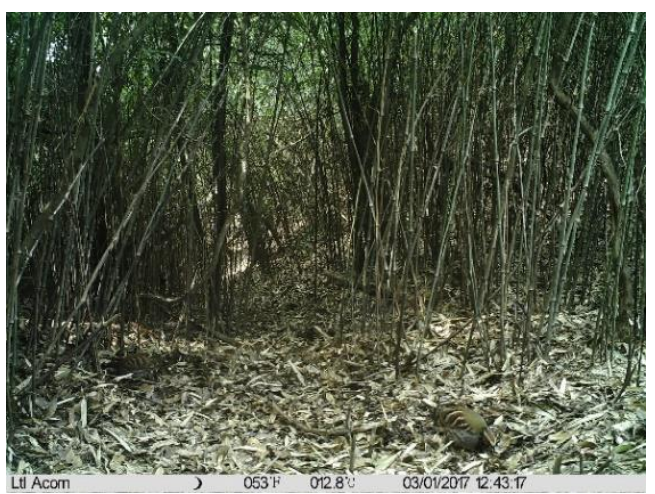

白眉山䳸鸪 Arborophila gingica

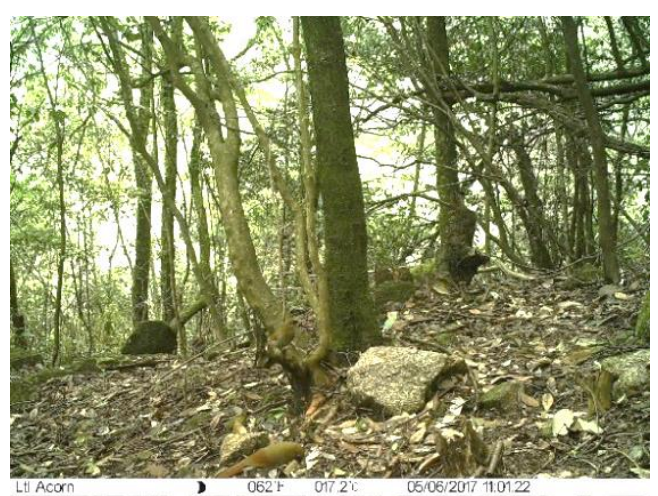

棕噪鸤 Garrulax poecilorhynchus 